\title{
Biomass-powered micro cogeneration system based on the modified Rankine Cycle operation - the initial tests
}

\author{
Krzysztof Sornek ${ }^{1, *}$, Wojciech Goryl ${ }^{1}$, and Mariusz Filipowicz ${ }^{1}$ \\ ${ }^{1}$ AGH University, Faculty of Energy and Fuels, Department of Sustainable Energy Development, \\ Mickiewicza Av. 30, 30-059 Krakow, Poland
}

\begin{abstract}
This paper shows results of initial tests of prototypical microcogeneration system based on the modified Rankine cycle operation. This system is powered by a $100 \mathrm{~kW}$ straw-fired batch boiler which was adapted to operate as a high temperature heat source. Thermal oil, heated up to $190-200^{\circ} \mathrm{C}$, transfers heat to two shell and tube heat exchangers (evaporator and superheater). Steam powers a 2-cylinder, double-acting, 20 -horsepower steam engine. Then, it is condensed in a condenser (another shell and tube heat exchanger) and pumped to the degasser. Finally, condensate is pumped to the evaporator and the whole process starts again. The steam engine is connected with a power generator. The operation of the developed micro-cogeneration system is controlled by the control and measurement system based on WAGO PFC200 PLC controller. The following parameters are recording: temperature, pressure and medium flow (in the boiler, oil, steam and water circuits). The results of the initial tests are promising. Power generated in the system is actually about $1,0 \mathrm{~kW}$ el. Such power is sufficient for supplying a part of the system's equipment. On the other hand, it is finally expected to ensure selfsufficient operation of the tested system.
\end{abstract}

\section{Introduction}

Distributed generation (DG) based on renewable energy sources (RES), is an attractive option e.g. for residential and agricultural sectors. In Polish conditions, one of the most promising RES is biomass which is characterized by wide availability, high caloric value, low prices and ability to decrease the dependency on fossil fuels. Analysing actually available combine heat and power generation (CHP) technologies dedicated to biomass utilization, there are several possibilities, including internal combustion piston engines, cogeneration plants with a steam/vapour turbine working on a Rankine Cycle (RC) or Organic Rankine Cycle (ORC), Stirling engines and thermoelectric generators [1,2]. The above mentioned technologies are a part of many worldwide studies focused on the use of biomass-based technologies for combined heat and power generation.

\footnotetext{
${ }^{*}$ Corresponding author: krzysztof.sornek@agh.edu.pl
} 
For example, in [3] three variants of the CHP plant based on the Organic Rankine Cycle and fuelled with sawmill waste have been analysed. A $250 \mathrm{~kW}_{\text {th }}$ boiler was used as a heat source. Working fluids like: methanol, octamethyltrisiloxane, methylcyclohexane and water were analysed. The highest electric power was obtained for the system with internal regeneration and methylcyclohexane applied as the dry working fluid. The highest temperature to supply the drying chamber was obtained for the system with external regeneration and octamethyltrisiloxane applied as the working fluid. Another example of a CHP system was shown in [4], where the ORC system, characterized by an electricity output of $2 \mathrm{~kW}_{\mathrm{el}}$, was tested. The electrical efficiency of this system varied between 7.5 and $13.5 \%$, depending on the hot water temperature from the biomass boiler and the condenser cooling water temperature. On the other hand, in [5] the operation of an experimental ORC system based on a $50 \mathrm{~kW}$ pellet-fired boiler was observed, with a maximum electrical power obtained at a level of $860 \mathrm{~W}$. The heat obtained from biomass combustion in the boiler was used to produce hot water, which was used to vaporize the organic working fluid in the evaporator. Other aspects, such as an economical and environmental conditions of using biomass-fired heating and CHP systems, were presented e.g. in [6,7,8]. Investigations carried out confirm that it is possible to develop and introduce environmental friendly units, characterized by a relatively short pay-back period (e.g. few years).

Although a lot of research work has been carried out on the biomass-based combined cycle configurations, technical advances are still needed. This paper shows selected aspects of the operation of a prototypical micro cogeneration system with the $100 \mathrm{~kW}_{\text {th }}$ straw-fired boiler. It is the second approach to extend the functionality of a heating boiler with a power generation system (the first one, based on the $180 \mathrm{~kW}_{\text {th }}$ straw-fired boiler equipped with special heat exchanger located after the second combustion chamber was described in [9]).

\section{Experimental rig}

Based on the previously conducted studies, a biomass-powered micro cogeneration system using modified Rankine cycle operation was developed. The high temperature heat source is a $100 \mathrm{~kW}_{\text {th }}$ straw-fired batch boiler. This boiler has an oil jacket (replacing typically used water jacket) and is equipped with a dedicated fuel feeder. Steam is generated in two shell and tube heat exchangers, operating respectively as an evaporator and a superheater. Generated steam is conditioned using a moisture separator and a reducing valve, and then powers a 2-cylinder, double-acting, 20-horsepower steam engine. Then, it is condensed in a condenser (another shell and tube heat exchanger) and pumped to a degasser. Finally, condensate is pumped to the evaporator and the whole process starts again. Electricity is generated in a power generator connected with the steam engine. The main elements of the developed micro cogeneration system are shown in Fig. 1.
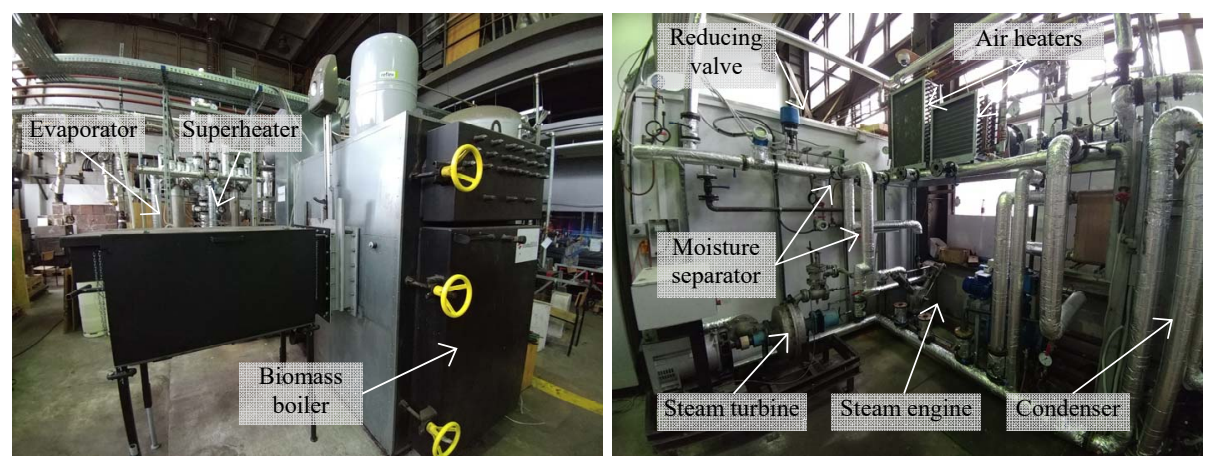

Fig. 1. The main elements of the developed micro cogeneration system. 
The operation of the developed micro-cogeneration system is controlled by the control and measurement system based on WAGO PFC200 modular PLC controller. Such parameters are recording: temperature, pressure and medium flow (in the boiler, oil, steam and water circuits), and current and voltage generated in the power generator. The control of the system's operation is performed by inverters adjusting the flow of the inlet air, flue gas, thermal oil, condensate and cooling water. All parameters may be observed and recorded via CoDeSys software using especially developed visualisation.

\section{Results and discussion}

During presented tests, $102 \mathrm{~kg}$ of straw was burned (13 rectangular straw bales with mass varied from 7.1 to $8.7 \mathrm{~kg}$ and average moisture content lower than $10 \%$ ). Obtained results show the most important parameters of the boiler, the oil circuit and the steam circuit operation.

\subsection{Boiler's operation}

Control of the boiler operation was realized via the inlet air fan and the flue gas fan setting using measured values of flue gas and oil temperature. Flue gas temperature was maintained at a level of $320-340^{\circ} \mathrm{C}$, while oil was heated up to $208^{\circ} \mathrm{C}$. Straw was loaded to the combustion chamber in portions by the fuel feeder. In the starting and combustion phases, flue gas fan operated with higher power than inlet air fan. Only in the afterburning phase, when straw situated in the front part of combustion chamber was burned, inlet air fan was set at higher power comparing to flue gas fan.

As was shown in Fig. 2, temperature of the flue gas varied in the range from 200 to $400^{\circ} \mathrm{C}$, so continuous control was required - relative power of the fans was varied from 30 to $100 \%$. Variations in the oil temperature were relatively low, but they significantly impacted the steam parameters (from the standpoint of steam generation it was really important to ensure constant oil temperature).

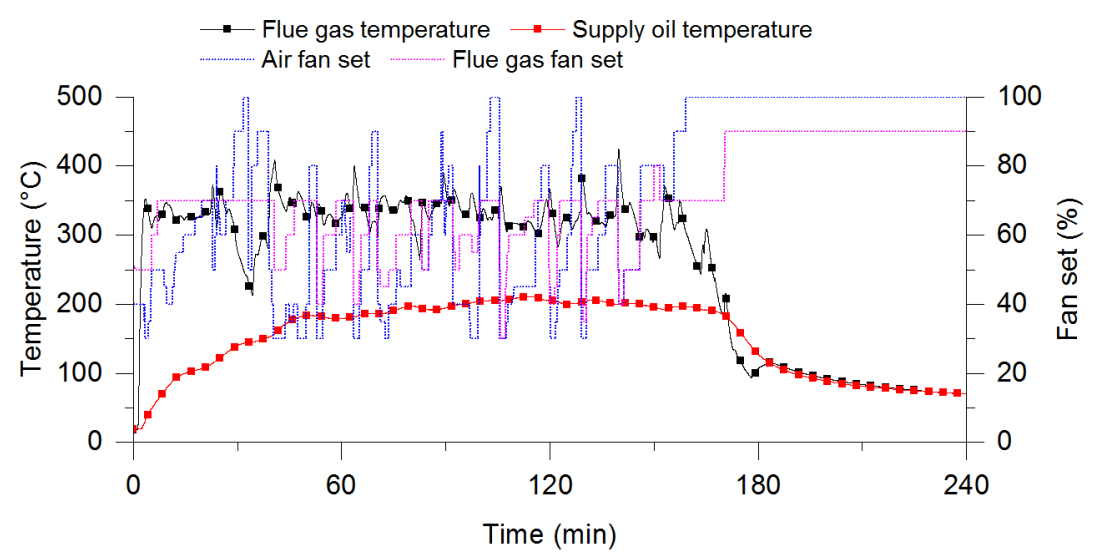

Fig. 2. The variations in the flue gas temperature, oil temperature as well as air fan ad flue gas fan.

Heat generated in the boiler was transferred by the oil circuit to condensate (evaporator and superheater) and water (emergency heat exchanger). The maximum thermal power taken from the oil circuit to evaporate condensate was at a level of ca. $90 \mathrm{~kW}$ (it was about $90 \%$ of thermal power generated in the boiler). On the other hand, the maximum thermal power reached in the boiler was ca. $190 \mathrm{~kW}$ during the time when the emergency heat 
exchanger was switched on (between 160 and 180 minutes of the combustion process). Variations in the thermal power generation in the boiler as well as the thermal power taken by condensate inside the evaporator, the superheater and the emergency heat exchanger; are shown in Fig. 3.

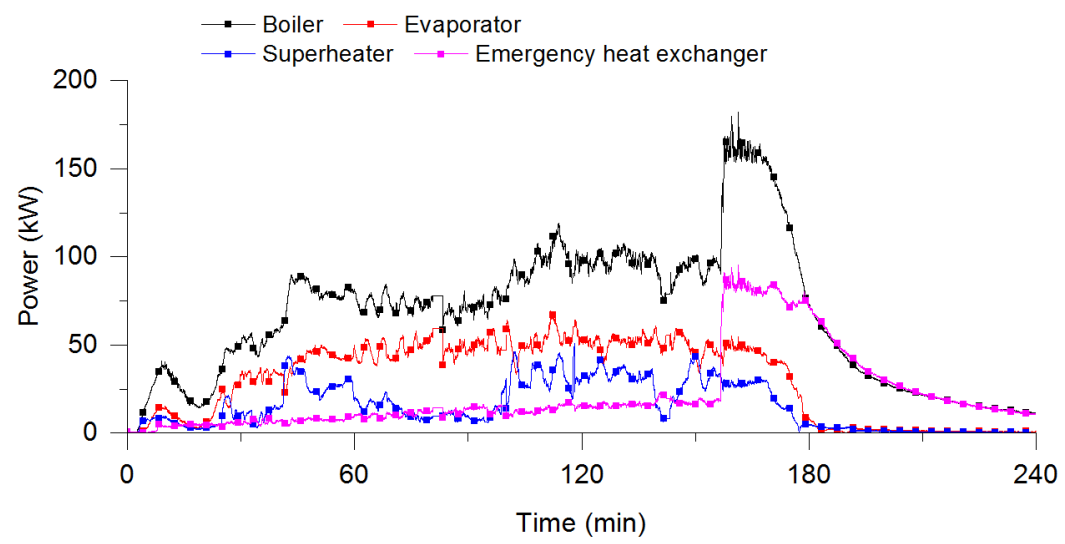

Fig. 3. Variations in the thermal power generation in the boiler as well as thermal power taken by the evaporator, the superheater and the emergency heat exchanger.

\subsection{Steam circuits parameters}

From the standpoint of a power generation system, it was very important to provide high temperature, pressure and flow of the steam. In the developed system, the maximum level of steam pressure was 5.8 bars, and temperature at the outlet from superheater $-198^{\circ} \mathrm{C}$. On the other hand, when power generated in the generator achieved the highest level, steam pressure dropped to 4.3 bars. Steam mass flow was then equal to $107 \mathrm{~kg} / \mathrm{h}$, which allowed generating power at a level of $1050 \mathrm{~W}$ (at a rotation speed of the steam engine $372 \mathrm{RPM}$ ). The main parameters measured in the steam circuit are shown in Fig. 4.

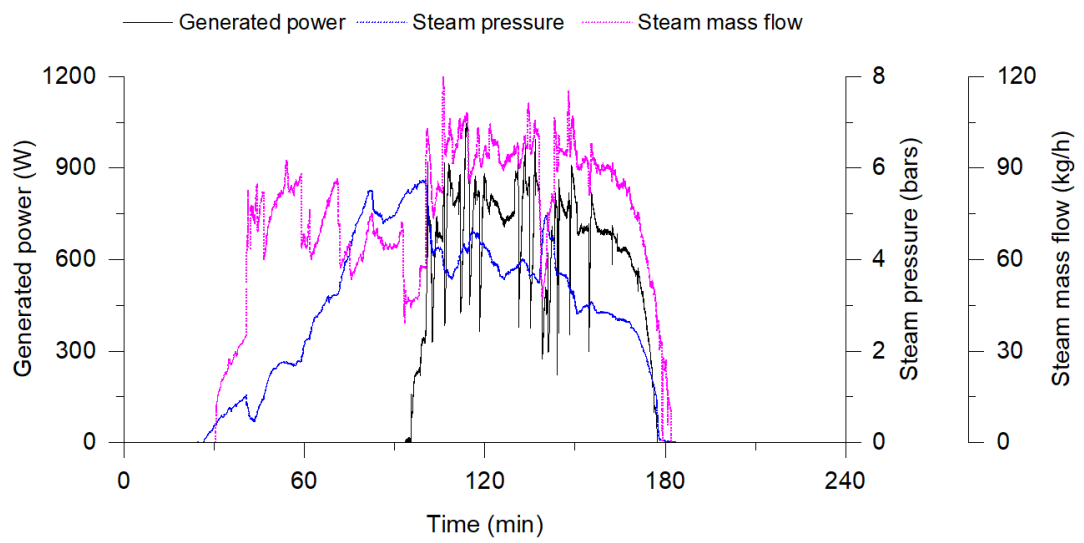

Fig. 4.Variations in the steam pressure, temperature and power generated in the power generator.

The current-voltage (I-V) power-voltage $(\mathrm{P}-\mathrm{V})$ characteristics are shown in Fig. 5. The maximum power was reached for voltage equal to $277.8 \mathrm{~V}$ and current equaling $3.65 \mathrm{~A}$. Achieved power was limited both by steam parameters and construction of the power generator - the obtained value is only $10.7 \%$ of the nominal power of the used steam engine 
(nominal power of the installed steam engine, given by manufacturer, is ca. $14 \mathrm{~kW}$, when pressure is 13.8 bars and rotation speed is $700 \mathrm{RPM}$ ).
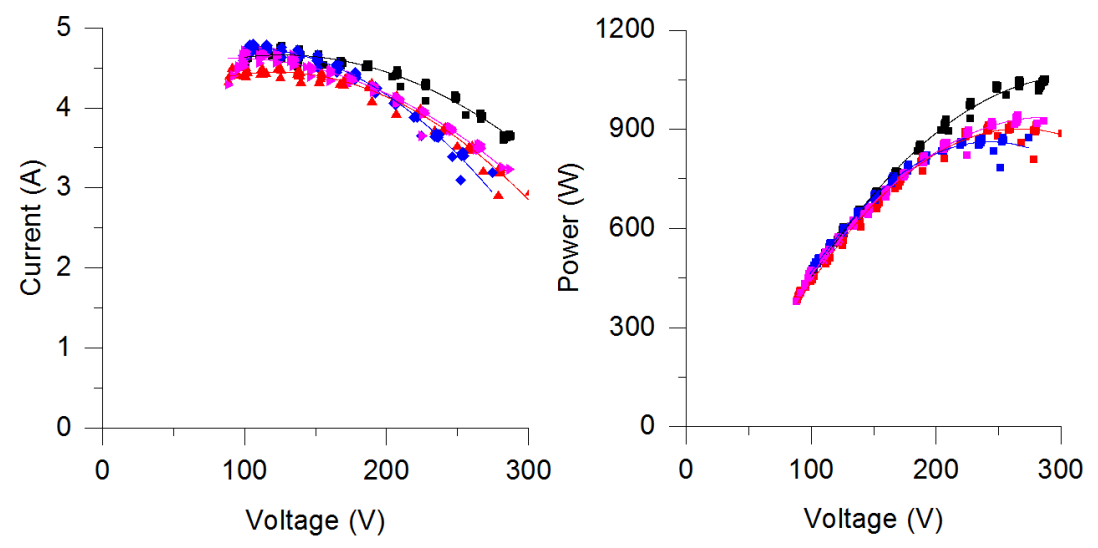

Fig. 5. Current-voltage (I-V) and power-voltage (P-V) characteristics of the power generator.

\section{Conclusion}

Initial tests of the developed micro cogeneration system confirm the possibility of increased functionality of straw-fired boiler with a power generation. Many further tests, to provide high efficiency and reliability of the installation, are still required. At this time, maximum power generated in the system was at a level of $1.050 \mathrm{~kW}_{\mathrm{el}}-$ it is expected to achieve at least 1.5-2 times higher power value by simple optimizing the existing system's configuration and by improved control of the complete set of the processes.

The work has been completed as part of the statutory activities of the Faculty of Energy and Fuels at the AGH UST in Krakow "Studies concerning the conditions of sustainable energy development", using the data obtained during the fulfilment of the project entitled: "BioORC: Construction of cogeneration system with small to medium size biomass boilers".

\section{References}

1. D. Champier, J.P. Bedecarrats, T. Kousksou, M. Rivaletto, F. Strub, Energy 36 (3), 1518-26 (2011)

2. K. Sornek, M. Filipowicz, K. Rzepka, Energy Convers. Manage, 125, 185-193 (2016)

3. A. Borsukiewicz-Gozdur, S. Wiśniewski, S. Mocarski, M. Bańkowski, Energy Convers. Manage., 87, 1180-1185 (2014)

4. H. Liu, Y. Shao, J. Li, Biomass Bioenergy, 35, 3985-3994 (2011)

5. G. Qiu, Y. Shao, L. Jinxing, H. Liu, S.B. Riffat, Fuel, 96, 374-382 (2012)

6. M. Uris, J.I. Linares, E. Arenas, Renewable Energy, 66, 707-713 (2014)

7. A. Algieri, P. Morrone, Appl. Therm. Eng., 71, 751-759 (2014)

8. E.F. Kristensen, J.K. Kristensen, Biomass and Bioenergy, 26 (6), 561-569 (2004)

9. K. Sornek, M. Filipowicz, Chemical and Process Engineering, 37 (4), 503-515 (2016) 